\title{
Tata letak tanaman pada rumah berkonsep arsitektur tradisional Bali di Kota Bangli, Kabupaten Bangli Provinsi Bali
}

\author{
I Dewa Gede Agung Surya Pranditha ${ }^{1}$, Anak Agung Gede Sugiantara ${ }^{1 *}$, Ni Luh Made Pradnyawathi ${ }^{2}$
}

1. Program Studi Arsitektur Pertamanan, Fakultas Pertanian, Universitas Udayana, Indonesia

2. Program Studi Agroekoteknologi, Fakultas Pertanian, Universitas Udayana, Indonesia

*E-mail : sugianthara@unud.ac.id

\begin{abstract}
The plants layout on Balinese traditional architecture concept houses in Bangli City, Bangli Regency, Bali Province. Bangli Regency is one of the regency that located in the central part of Bali island and only one of regency do not have sea. Balinese Traditional Architecture can be interpreted as the spatial from the life place of Balinese community that has developed through generations with all the rules are inherited from ancient times, until the development of a form with the physical characteristics are revealed on the Lontar Asta Kosala-Kosali. The traditional Balinese park is not only involved the architectural, functional, aesthetic, but also used Balinese cultural philosophy in every placement of it landscape components. The purpose of this research were to understand the effect of land to the application Balinese Traditional Architecture, to understand the concept are using on development house in the city of Bangli regency and then to know how the sense of Balinese traditional architecture on the houses in Bangli city, Bangli regency. The result of the study was that the land area is very influential on the implementation of Traditional Balinese Architecture because there are rules that should be applied that is Asta Kosala-Kosali, the concept applied is Tri Hita Karana, Tri Mandala dan Tri Angga. Plants layout on Balinese people's knowing is very less, so in plant layouting people only accentuate the aesthetic without a Balinese cultural philosophy.
\end{abstract}

Keywords: Balinese traditional architecture, Bangli regency, Balinese traditional park, Tri Mandala

\section{Pendahuluan}

Kota merupakan cerminan kehidupan yang dikatakan telah mengalami kemajuan yang kompleks, sering dikaitkan dengan pemahaman bahwa kota merupakan pusat dari perkembangan ilmu pengetahuan dan teknologi. Kota yang menjadi tolak ukur sebagai percontohan pembangunan yang maju, kota sebagai kesatuan jaringan kehidupan manusia yang ditandai dengan kepadatan penduduk yang tinggi dan diwarnai dengan strata sosial ekonomi yang heterogen serta coraknya materialistis. tetapi masih terdapat permasalahan, salah satunya yaitu keterbatasan lahan di daerah perkotaan sebagai tempat tinggal manusia akibat dari kepadatan penduduk ( Bintarto 1983).

Arsitektur tradisional Bali merupakan arsitektur yang berlandaskan pada ajaran Agama Hindu yang memang berkembang pada jamannya, dan sekarang merupakan warisan dari para generasi sebelumnya. Arsitektur Tradisional Bali dapat diartikan sebagai tata ruang dari wadah kehidupan masyarakat Bali yang telah berkembang secara turun-temurun dengan segala aturan-aturan yang diwarisi dari zaman dahulu, sampai pada perkembangan satu wujud dengan ciri-ciri fisik yang terungkap pada lontar Asta Kosala-Kosali, Asta Patali (Dwijendra Acwin, 2008).

Seiring dengan perkembangan jaman semakin banyak model bangunan yang ada dan tidak memerlukan biaya yang besar seperti jika menerapkan konsep arsitektur tradisional Bali, sehingga minat masyarakat untuk tetap menerapkan konsep arsitektur tradisioal Bali menurun. Terus meningkatnya kepadatan penduduk di daerah perkotaan khususnya Kota Bangli semakin terbatas pula lahan untuk tempat tinggal, oleh karena itu penerapan konsep arsitektur tradisional Bali pada kawasan perkotaan dapat berkurang karena penerapan konsep arsitektur tradisional Bali memerlukan lahan yang tidak sedikit, komponen yang dipakai landasan dalam membuat atau mendesain sebuah taman atau lanskap di Bali, yang harus sesuai 
dengan unsur Satyam (kebenaran), Siwam (kebersihan, kesucian, kemuliaan), Sundaram (keindahan, kecantikan, keharmonisan) yang menjiwai konsep Tri Hita Karana, Tri Mandala, Tri Angga maupun Asta Dala. Penelitian bertujuan untuk mengetahui pengaruh lahan terhadap penerapan konsep arsitektur tradisional Bali, dan mengetahui bagaimana tata letak tanaman pada rumah berkonsep ArsitekturTradisional Bali di Kota Bangli, Kabupaten Bangli.

\section{Metode Penelitian}

\subsection{Waktu dan Tempat Penelitian}

Penelitian dilakukan di Kota Bangli, Kecamatan Bangli, Kabupaten Bangli yang dilakukan selama sembilan bulan dari tahap persiapan sampai pelaporan yaitu dari Bulan November 2016 sampai dengan Agustus 2017.

\subsection{Alat Penelitian}

Alat yang digunakan dalam penelitian ini adalah akat tulis, handphone untuk merekam suara, serta computer untuk mengolah data dengan menggunakan software Microsoft Office Word dan software AutoCAD, software Google Earth, lembar kuisioner dan lembar wawancara.

\subsection{Metode Penelitian}

Penelitian ini menggunakan metode survei dengan teknik pengumpulan data dengan menggunakan teknik observasi dan wawancara serta menggunakan kuisioner untuk mendapatkan data primer, sedangkan data sekunder diperoleh dengan teknik studi literatur. menurut Bailey (1982) metode penelitian survei merupakan satu metode penelitian yang teknik pengambilan datanya dilakukan melalui pertanyaan tertulis atau lisan.

\subsection{Teknik Pengumpulan Data}

Teknik pengumpulan data yang dilakukan dalam penelitian ini adalah dengan wawancara, penyebaran kuisioner, observasi, dan kepustakaan serta dokumentasi.

a. Wawancara, jenis wawancara yang digunakan adalah wawancara berstruktur dengan membuat pedoman pertanyaan sebagai pemandu yang bersifat tentative (dapat dikembangkan sesuai dengan kemajuan penelitian di lapangan) agar wawancara yang dilakukan dapat terfokus.

b. Penyebaran kuisioner merupakan teknik pengumpulan data yang dilakukan untuk memperoleh informasi dengan memberikan angket kepada 30 pemilik rumah di Kelurahan Cempaga dan Kelurahan Kawan Kecamatan Bangli. Menurut Reimundo (2014) karena asumsi distribusi normal saat perhitungan ketika jumlah sampel mencapai 30.

c. Observasi, tipe observasi dalam penelitian ini digolongkan ke dalam observasi non partisipan. Peneliti mengamati keadaan rumah tetapi peneliti tidak melakukan partisipasi terhadap kegiatan yang ada. Observasi ini dibantu oleh alat rekam gambar berupa kamera.

d. Studi kepustakaan adalah data yang diperoleh melalui pengambilan dari buku-buku, literatur-literatur, catatan-catatan, laporan-laporan maupun internet serta informasi yang disimpan atau didokumentasikan sebagai bahan dokumentasi yang ada hubungannya dengan masalah yang dipecahkan (Nazir, 1998).

\subsection{Cara Pemilihan Sampel}

Pendekatan yang digunakan dalam pemilihan objek penelitian adalah pendekatan sampel. Cara pengambilan sampel yang digunakan adalah purposive sampling. Adapun sampel penelitian dipilih dengan beberapa pertimbangan, antara lain:

a. Pemilihan sampel harus dapat membantu menjawab rumusan masalah penelitian yang berupaya untuk mengetahui tata letak tanaman pada rumah berkonsep Arsitektur Tradisional Bali.

b. Banyaknya lokasi penelitian mengakibatkan jumlah sampel harus dapat menghasilkan efektifitas penelitian. Artinya, jumlah sampel yang digunakan telah menjawab rumusan masalah dengan memenuhi target waktu penelitian. Hal ini dilakukan dengan mengambil 30 sampel rumah yang berada di Kota Bangli, Kabupaten Bangli.

C. Objek penelitian yang diambil sebagai sampel penelitian harus memenuhi kriteria. Kriteria yang menjadi sampel dalam penelitian ini adalah: 1) Masyarakat asli Bangli yang tinggal di Kota Bangli; 2) Masyarakat yang beragama Hindu; 3) Masyarakat yang bersedia di wawancarai.

\subsection{Metode Analisis data}

Metode analisis data menurut Silalahi (2006) meliputi tahap pengolahan data hasil obeservasi, kuisioner dan wawancara. Metode yang digunakan adalah tabulasi, analisis spasial dan analisis deskriptif. 
1. Tabulasi

Menurut Sudjana (2001), teknik tabulasi data ini digunakan untuk menghitung jumlah pilihan responden (f) dibandingkan dengan jumlah keseluruhan responden $(\mathrm{N})$ ke dalam bentuk presentase (\%) dengan dikali 100 persen. Perhitungan presentase seperti dikemukakan Sudjana adalah sebagai berikut:

Keterangan:

$$
P=f / N \times 100 \%
$$

$\mathrm{P}=$ Presentase

$\mathrm{F}=$ Frekuensi

$\mathrm{N}=\Sigma$ Total Responden

\section{Analisis Spasial}

Analisis spasial merupakan analisis untuk mengukur distribusi suatu kejadian berdasarkan aspek keruangan. Analisis spasial akan menghasilkan sebuah denah hasil analisis (Tuman, 2001).

\section{Analisis Deskriptif}

Sugiyono (2004) menyatakan bahwa analisis deskriptif adalah metode yang digunakan untuk menganalisis data dengan cara mendeskripsikan atau menggambarkan data yang telah terkumpul tanpa bermaksud membuat kesimpulan yang berlaku untuk umum.

\subsection{Batasan Penelitian}

Penelitian ini merupakan penelitian mengenai bagaimana tata letak tanaman pada rumah berkonsep Arsitektur Tradisional Bali di Kota Bangli, Kabupaten Bangli. Penelitian ini terbatas dilakukan di Kota Bangli khususnya di Kelurahan Kawan dan Kelurahan Cempaga. Tahap studi dilakukan dengan cara melakukan pengamatan, penyebaran kuesioner dan wawancara terhadap informan.

\section{Hasil dan Pembahasan}

\subsection{Keadaan Geografis}

Kabupaten Bangli memiliki luas 520,81 km atau 9,25 persen dari luas wilayah Provinsi Bali. Dilihat dari pembagian wilayah, Bangli hanya memiliki 4 kecamatan dan 72 desa/kelurahan. Kecamatan Bangli merupakan wilayah dengan zona daerah pusat pemerintahan, pusat pendidikan, pusat perdagangan dan jasa. Kecamatan Bangli memiliki dua kelurahan yang terdapat di pusat kota Kabupaten Bangli, yaitu Kelurahan Kawan dan Kelurahan Cempaga.

\subsection{Penduduk}

Laju pertumbuhan penduduk di Kecamatan Bangli relatif kecil, dengan penduduk terbanyak ada di Kelurahan Kawan yaitu sekitar 17 persen dan Kelurahan Cempaga sekitar 16 persen. Penduduk Kelurahan Kawan yaitu 10.568 orang dengan kepadatan penduduk 2.009 jiwa $/ \mathrm{km}^{2}$, sedangkan di Kelurahan Cempaga jumlah penduduk 7.744 orang (Profil Desa Dan Kelurahan Kecamatan Bangli Tahun 2016).

\subsection{Hasil Kuisioner Pemahaman Arsitektur Tradisional Bali pada Rumah di Kota Bangli, Kabupaten}

\section{Bangli.}

Hasil Kuisioner tentang pemahaman masyarakat pada arsitektur tradisional Bali pada Rumah di Kota Bangli, kabupaten Bangli, berdasarkan dari 30 sampel yang diambil dari dua kelurahan, disajikan pada Tabel 1.

Tabel 1. Hasil Kuisioner tentang Pemahaman Arsitektur Tradisional Bali

\begin{tabular}{clccc}
\hline & & \multicolumn{3}{c}{ Jawaban } \\
No & \multicolumn{1}{c}{ Data } & Ya & Tidak & Total \\
\hline 1 & Memahami konsep arsitektur tradisional Bali & $57 \%$ & $43 \%$ & $100 \%$ \\
2 & Memahami tentang tata letak dan fungsi dari bangunan & $88 \%$ & $12 \%$ & $100 \%$ \\
3 & Setiap bangunan berfungsi secara baik atau tidak & $90 \%$ & $10 \%$ & $100 \%$ \\
4 & Memahami tentang arsitektur tradisional Bali & $93 \%$ & $7 \%$ & $100 \%$ \\
5 & Mengetahui ukuran setiap bangunan pada arsitektur tradisional Bali & $59 \%$ & $41 \%$ & $100 \%$ \\
\hline
\end{tabular}


Lanjutan Tabel 1

\begin{tabular}{|c|c|c|c|c|}
\hline \multirow[b]{2}{*}{ No } & \multirow[b]{2}{*}{ Data } & \multicolumn{3}{|c|}{ Jawaban } \\
\hline & & $\mathrm{Ya}$ & Tidak & Total \\
\hline 6 & Memahami fungsi dari jenis-jenis bangunan pada pekarangan rumah & $80 \%$ & $20 \%$ & $100 \%$ \\
\hline 7 & Memahami fungsi dari jenis-jenis tanaman pada pekarangan rumah & $43 \%$ & $57 \%$ & $100 \%$ \\
\hline 8 & Memahami tentang tata letak dan fungsi dari tanaman & $40 \%$ & $60 \%$ & $100 \%$ \\
\hline
\end{tabular}

3.4 Hasil Observasi dan Wawancara Hubungan Luas Lahan dan Konsep Arsitektur Tradisional Bali yang Diterapkan pada Rumah di Kota Bangli, Kabupaten Bangli

Hasil observasi dan wawancara dengan 30 responden untuk mengetahui pengaruh lahan terhadap penerapan konsep Arsitektur tradisional Bali dan untuk mengetahui konsep-konsep arsitektur tradisional Bali yang diterapkan pada rumah di kota Bangli, kabupaten Bangli, menurut masyarakat lahan sangat berpengaruh terhadap penerapan arsitektur tradisional Bali dan terdapat tiga konsep arsitektur tradisional Bali yang diterapkan, dapat dilihat pada Tabel 2.

Tabel 2. Hasil Observasi dan Wawancara Pengaruh Luas Lahan dan Konsep-konsep Arsitektur Tradisional Bali Yang Diterapkan Pada Rumah di Kota Bangli, Kabupaten Bangli

\begin{tabular}{|l|l|l|l|l|}
\hline NO & Pertanyaan & Ya & Tawaban & Tidak \\
\hline 1 & $\begin{array}{l}\text { Apakah menurut anda luas } \\
\text { lahan berpengaruh terhadap } \\
\text { penerapan konsep arsitektur } \\
\text { tradisional Bali? }\end{array}$ & $100 \%$ & $0 \%$ & $100 \%$ \\
\hline 2 & $\begin{array}{l}\text { Menurut anda apakah } \\
\text { menerapkan konsep arsitektur } \\
\text { tradisional Bali itu penting }\end{array}$ & $100 \%$ & $0 \%$ & $100 \%$ \\
\hline 3 & $\begin{array}{l}\text { Apakah anda mengetahui } \\
\text { tentang tata letak tanaman } \\
\text { dalam konsep arsitektur } \\
\text { tradisional Bali }\end{array}$ & $24 \%$ & $76 \%$ & $100 \%$ \\
\hline 4 & $\begin{array}{l}\text { Menerapkan konsep THK } \\
5\end{array}$ & $100 \%$ & $0 \%$ & $100 \%$ \\
\hline
\end{tabular}

Keterangan: THK: Tri Hita Karana, TM: Tri Mandala, TA: Tri Angga.

\subsection{Hasil Wawancara Pengaruh Luas Lahan terhadap Penerapan Konsep Arsitektur Tradisional Bali}

Berdasarkan hasil wawancara dengan 30 responden tentang pengaruh luas lahan terhadap penerapan konsep arsitektur tradisional Bali seluruh masyarakat yakin bahwa luas lahan sangat berpengaruh terhadap penerapan konsep arsitektur tradisional Bali karena dalam penerapan arsitektur tradisional Bali memang sudah ada aturan yang menentukan salah satunya yaitu sikut natah, dikarenakan sikut natah dapat diketahui dan sudah dimuat dalam Asta Bumi, Asta Kosala-kosali, Tri Angga dan Asta dala. Dalam menentukan sikut natah harus didasarkan pada asta wara, yaitu sri, indra, guru, yama, ludra, brahma, kala dan uma, yang dapat menentukan ukuran natah dan menambahkan urip.

Menurut Dwijendra (2008), luas lahan sangat berpengaruh terhadap penerapan arsitektur tradisional Bali karena setiap bangunan yang dibuat harus mengikuti aturan yang sudah ada. Asta Kosala-Kosali sebagai pedoman untuk menentukan ukuran dari setiap bangunan, dan jarak antar bangunan sudah ada aturannya sehingga lahan yang digunakan untuk menerapkan konsep arsitektur tradisional Bali tidaklah sedikit. Tata letak dan cara mengukur bangunan tradisional Bali dapat dilihat pada Gambar 1. 


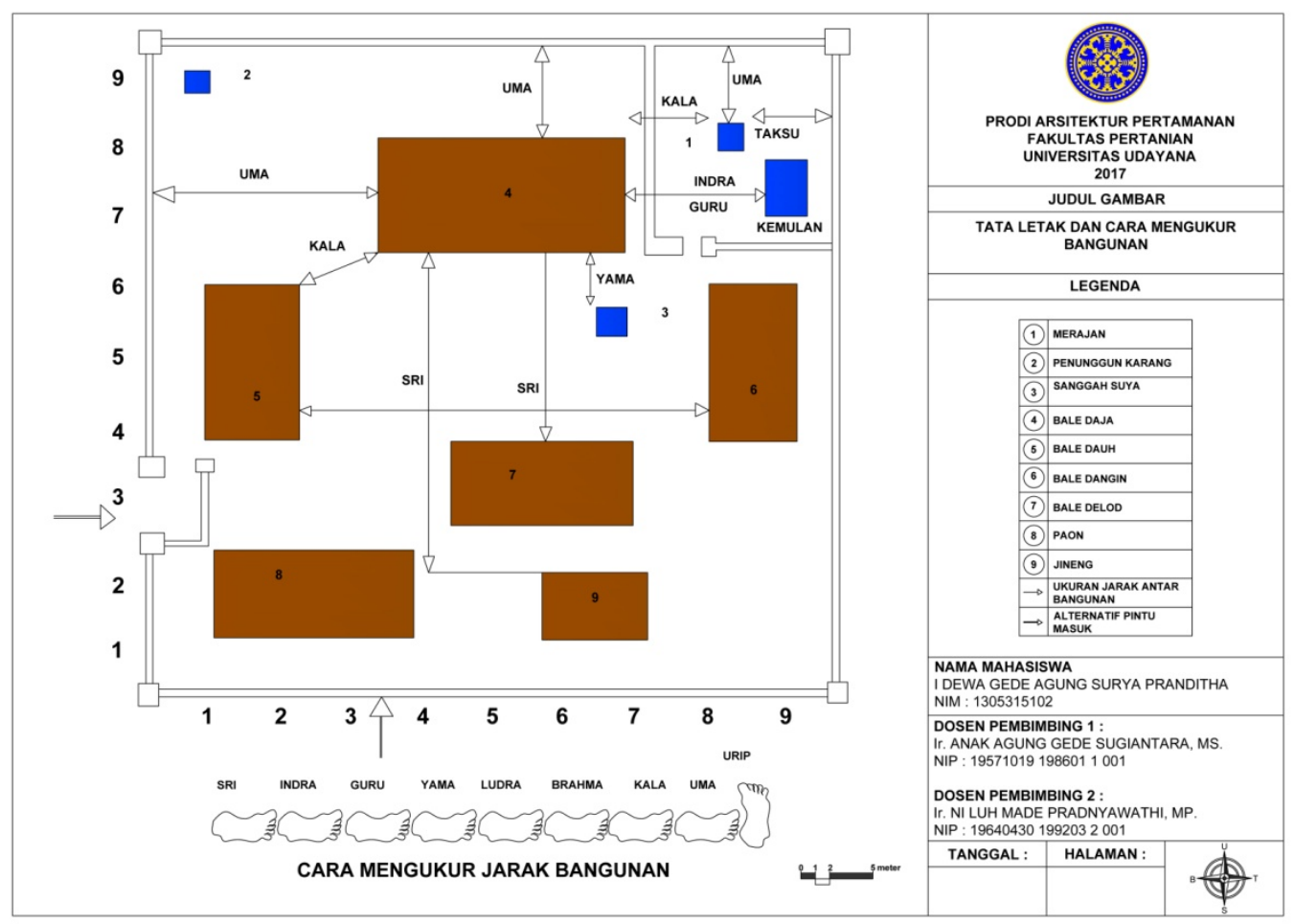

Gambar 1. Tata Letak dan Jarak Bangunan

3.6 Hasil Observasi dan Wawancara Konsep-konsep Arsitektur Tradisional Bali yang Diterapkan pada Rumah di Kota Bangli, Kabupaten Bangli

Berdasarkan hasil observasi dan wawancara mengenai konsep-konsep atsitektur tradisional Bali yang digunakan pada rumah di Kota Kabupaten Bali, dari 30 rumah yang menjadi sampel seluruh rumah menerapkan konsep dasar dari arsitektur tradisional Bali yaitu Tri Hita Karana dan Tri Mandala. Tri Hita Karana adalah Tri yang berarti tiga Hita berarti keharmonisan dan karana berarti penyebab sehingga dapat diartikan tiga penyebab keharmonisan, (Dwijendra Acwin,2008). Konsep Tri Hita Karana dipakai dalam pola ruang, dalam skala rumah dapat dilihat pada adanya pura/merajan (parhyangan) sebagai tempat hubungan manusia dengan pencipta/tuhan, tempat tinggal/bangunan (pawongan) sebagai tempat hubungan manusia dengan manusia dan natah/pekarangan (palemahan) sebagai tempat hubungan manusia dengan lingkungan.

Selain konsep Tri Hita Karana pada rumah di Kota Bangli, Kabupaten Bangli juga menerapkan konsep Tri Mandala. Tri Mandala berasal dari kata Tri yang berarti tiga dan Mandala yang berarti wilayah, atau daerah. Tri mandala dapat diartikan sebagai tiga wilayah yaitu Utama Mandala, Madya mandala dan Nista Mandala, (Sardiana dkk, 2012). Penerapan konsep Tri Mandala pada rumah di Kota Bangli, Kabupaten Bangli dapat dilihat dari pembagian ruang yang ada pada rumah tersebut. Terdapat tiga pembagian ruang yaitu Utama Mandala yaitu ruang yang bernilai suci meliputi jeroan pura atau merajan, Madya Mandala merupakan bagian tengah atau pekarangan rumah yang berisi bangunan tempat tinggal, Nista Mandala berupa telajakan.

3.6.1 Penempatan tanaman berdesarkan Tri Mandala

Berdasarkan observasi dan wawancara yang dilakukan pada 30 rumah sampel menunjukan bahwa masyarakat Bangli dalam menata taman pekarangan rumahnya belum sesuai dengan filosofi Tri Mandala, namun sebagian kecil dari masyarakat Bangli dalam menempatkan tanaman sudah sesuai dengan filosofi Tri Mandala. Tri Mandala dapat diartikan sebagai tiga wilayah yaitu Utama Mandala, Madya Mandala dan Nista Mandala (Sardiana dkk, 2012).

Berdasarkan hasil observasi tanaman yang digunakan sebagai elemen lunak taman pekarangan rumah terdiri dari tanaman yang dimanfaatkan bunga, daun, buah, umbi dan batangnya. Tanaman yang dimanfaatkan daunnya paling banyak ditanam di areal Madya Mandala, alasannya karena masyarakat menganggap tanaman memberikan kesan sejuk dan nyaman. Menurut Sardiana dkk (2012), konsep taman di Utama Mandala diutamakan tanaman yang bagian bunga, daun dan batangnya berfungsi sebagai sarana upakara. Kenyataan di lapangan menunjukan tanaman yang dimanfaatkan daunnya sebagai sarana upakara paling banyak ditanam di Madya Mandala. 
Tanaman yang dimanfaatkan bunganya paling banyak ditanam di areal Madya Mandala. Alasan responden lebih banyak menanam tanaman yang dimanfaatkan bunganya di areal Madya Mandala karena menganggap tanaman yang bisa dimanfaatkan bunganya memiliki nilai estetika dan dapat digunakan sebagai upakara, sehingga dengan menanam di Madya Mandala keindahan bunga dapat selalu dinikmati. Berdasarkan filosofi Tri Mandala penempatan tanaman yang bagian bunganya dimanfaatkan dalam upakara sebaiknya diutamakan ditanam pada areal Utama Mandala.

Tanaman yang dimanfaatkan buahnya paling banyak ditanam di Madya Mandala karena responden dapat dengan mudah memetik dan menikmati buah dari tanaman. Menurut Prajoko (2012) berpendapat bahwa areal Madya Mandala sebaiknya ditanami tanaman bunga dan beberapa jenis tanaman buah seperti belimbing. Tanaman yang dimanfaatkan buahnya habitus pohon tidak disarankan ditanam di Utama Mandala karena dianggap dapat merusak kesucian Utama Mandala, sedangkan jika ditanam pada areal Madya dan Nista Mandala buah dari tanaman dapat dengan mudah dinikmati.

Tanaman yang dimanfaatkan umbinya paling banyak ditanam pada areal Madya Mandala alasan responden lebih banyak menanam tanaman yang dimanfaatkan umbinya di areal Madnya Mandala adalah karena sering digunakan untuk keperluan dapur, sehingga lebih mudah untuk mencarinya. Sesuai filosofi Tri Mandala tanaman yang dimanfaatkan umbinya sebaiknya ditanam di Madya atau Nista Mandala.

Tanaman yang dimanfaatkan batangnya seperti tebu paling banyak ditanam di Utama Mandala. Menurut Prajoko (2012) di areal Madya Mandala sebaiknya tidak ditanami tanaman yang berbuku-buku seperti kelapa, tebu dan sejenisnya, karena diyakini dapat menyebabkan terputus-putusnya kehidupan dan rejeki.

3.6.2 Penempatan Tanaman Berdasarkan Asta Dala

Berdasarkan hasil observasi dan wawancara diketahui bahwa sebagian besar masyarakat di Bangli dalam menata taman pekarangan rumah belum sesuai dengan filosofi Asta Dala. Masyarakat kurang memahami penempatan tanaman sesuai filosofi Asta Dala, walaupun dalam pembuatan sarana upakara sering menggunakan filosofi yang sama namun masyarakat tidak mengetahui bahwa filosofi Asta Dala dapat digunakan sebagai acuan untuk menata taman. Asta Dala adalah delapan penjuru arah mata angin, yaitu Utara, Timur Laut, Timur, Tenggara, Selatan, Barat Daya, Barat dan Barat Laut (Prajoko, 2012). Penempatan tanaman disesuaikan dengan arah mata angin terutama dilihat dari segi warna bunganya.

Penempatan tanaman sesuai filosofi Asta Dala yaitu berdasarkan warna daun, bunga dan buah juga harus tetap memperhatikan estetika. Sebagai contoh Utara merupakan stana Dewa Wisnu dengan warna hitam, Timur Laut stana Dewa Sambu dengan warna biru, Timur stana Dewa Iswara dengan warna putih, Tenggara stana Dewa Mahesora dengan warna dadu, Selatan stana Dewa Brahma dengan warna merah, Barat daya stana Dewa Rudra dengan warna oranye, Barat stana Dewa Mahadewa dengan warna kuning, dan Barat Laut stana Dewa Sangkara dengan warna hijau. Namun penempatan tanaman tidak harus hanya sesuai dengan warna, penempatan tanaman dapat dikombinasikan agar memiliki nilai estetika, namum tetap memunculkan dominan warna pada masing-masing arah sesuai filosofi Asta Dala. 


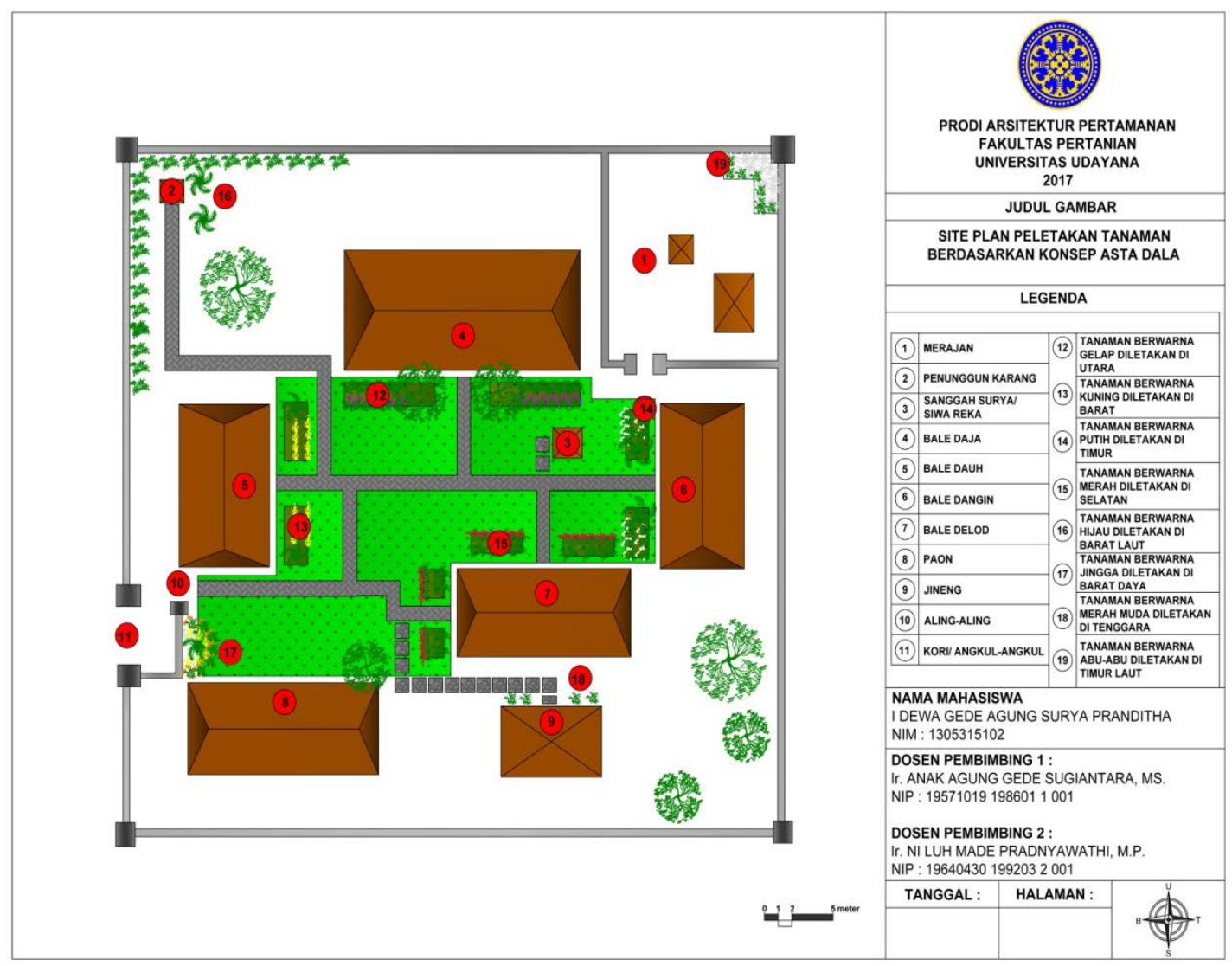

Gambar 2. Site Plan Peletakan Tanaman Berdasarkan Konsep Asta Dala

\section{Simpulan}

Luas lahan sangat berhubungan terhadap penerapan arsitektur tradisional Bali karena dalam menerapkan arsitektur tradisonal Bali ada aturan yang semestinya diterapkan yaitu Asta Kosala-Kosali sebagai pedoman untuk menentukan ukuran dari setiap bangunan, dan jarak antar bangunan, sedangkan di Kota Bangli dengan lahan yang terbatas masyarakat Bangli masih menerapkan arsitektur tradisional Bali tetapi tidak sepenuhnya menerapkan konsep Asta Kosala-Kosali sebagai pedoman untuk ukuran bangunan dan jarak antar bangunan. Sedangkan konsep arsitektur tradisional Bali yang diterapkan pada rumah di Kota Bangli, Kabupaten Bangli yaitu menerapkan Tri Hita Karana dan Tri mandala dengan peletakan tanaman yang digunakan oleh masyarakat hanya menonjolkan nilai estetika.

\section{Daftar Pustaka}

Bailey, 1982. Methods of social research: The free Press. New York

Bintarto, 1983. Urbanisasi dan Permasalahannya: Ghalia Indonesia. Yogyakarta

Dwijendra Acwin. 2008. Arsitektur rumah tradisional Bali. Udayana University Press. Denpasar

Nazir, M., 1998. Metode Penelitian: Ghalia Indonesia. Jakarta

Prajoko Ahmad. 2012.Pertamanan Tradisional Bali Berlandaskan Unsur Satyam, Siwam, Sundaram, Relegi dan Usada. Di akses online pada http://www.parissweethome.com/bali/cultural_my.php?id=11. Diakses pada tanggal 5 juni 2016

Reimundo, R. 2014. "Mengapa Jumlah Sampel Minimum 30". Tersedia online: http://www.raynaldoferrarireimundo.blogspot.co.id. (Diakses 15 Juni 2017)

Sardiana, I. K., Wayan P. Windia, I.G.N. Sudiana, Sundani N. Soewandhi, Ketut Sundra, Wayan Sudarka, Made Widnyana Sudibya, Ketut Kartha Dinata, Sang Made Sarwadana, Wayan Sukersa. 2010. Taman Gumi Banten: Ensiklopedia Tanaman Upakara. Udayana University Press. Denpasar.

Silalahi, U. 2006. Metode Penelitian Sosial. Unpar Press. Bandung.

Sudjana, D. 2001. Metode Statistika. Tarsito. Bandung.

Sugiyono, D. 2004. Metode Penelitian Bisnis. CV. Alfabeta. Bandung.

Tuman. 2001. Overview of GIS. Tersedia secara online di: www. Gisdevelopment.net. (Diakses 9 juli 2017) 